\title{
Men in maternity study: Men matter
}

\author{
Anjana Das \\ Leila Caleb-Varkey \\ Anurag Mishra \\ Population Council \\ Emma Ottolenghi \\ Dale Huntington
}

Follow this and additional works at: https://knowledgecommons.popcouncil.org/departments_sbsr-rh

Part of the Demography, Population, and Ecology Commons, Family, Life Course, and Society Commons, International Public Health Commons, and the Maternal and Child Health Commons How does access to this work benefit you? Let us know!

\section{Recommended Citation}

Das, Anjana, Leila Caleb-Varkey, Anurag Mishra, Emma Ottolenghi, and Dale Huntington. 2002. "Men in maternity study: Men matter," FRONTIERS Research Update. New Delhi: Population Council. 


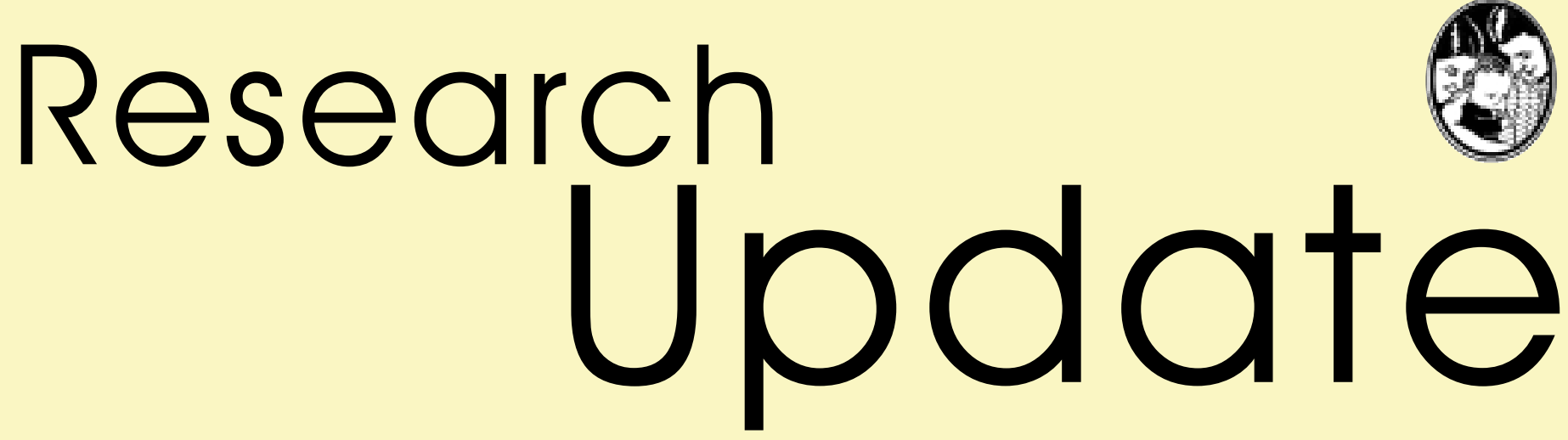

April 2002

No. 2

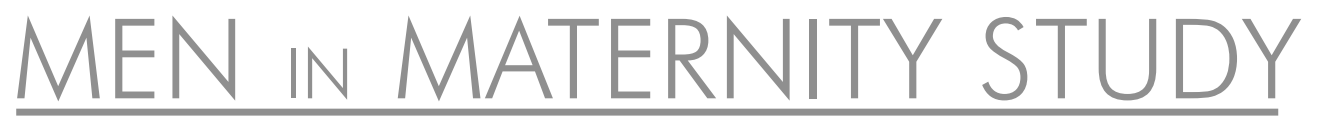

Men Matter

THINK REPRODUCtIVE HEALTH. THINK WOMEN? NOT ANYMORE.

The Population Council and the Employees' State

Insurance Corporation (ESIC) are collaborating on a Men in Maternity Study in India to test a model of antenatal and postnatal services designed to help thousands of couples, especially men, re-define their roles in reproductive health, improve birth outcomes and maternal health. This is part of a global study that will assess the impact of male partnership in improving pregnancy outcomes and reproductive health, primarily by reducing the prevalence of STIs and increasing postpartum family planning use.

Historically, reproductive health has focused on women's reproductive concerns and their empowerment. Reproductive health services have excluded or even alienated men. Cultural biases exist against allowing men into areas designed for the

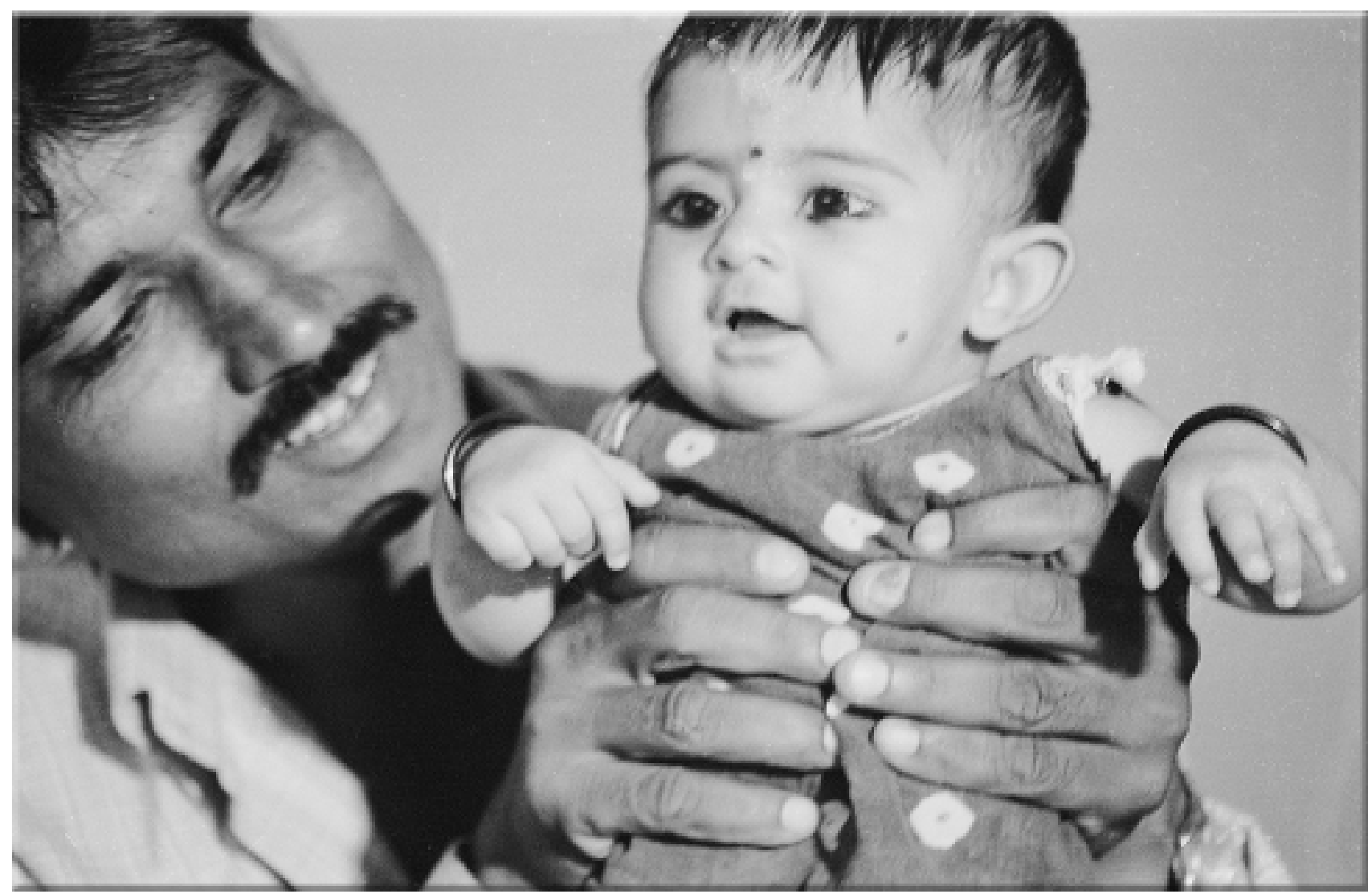


provision of reproductive health. But this is changing.

Studies suggest that the lack of men's participation in reproductive health actually undermines women's health (Biddlecom et al 1997). Health officials and even men themselves are becoming more aware of the critical role they play in reproductive health and many men are seeking an active part as partners and as fathers. Women's sexual and reproductive health choices, the use of contraception to prevent pregnancy, the prevention of HIV and other sexually transmitted infections often depend on the involvement of their male partners.

The Men in Maternity (MiM) Study is the first of its kind in India. It includes more than a focus on contraception or safe motherhood and covers topics ranging from child survival and postpartum services to STI diagnosis and treatment and prevention of HIV/AIDS.

This Research Update No. 2 provides an overview of the MiM experimental intervention and some lessons learned in establishing the new services and maintaining operations during the first 14 months of the study's intervention period.

\section{Background}

IN SOCIETIES WHERE THE UNDERLYING SOCIAL STRUCTURES of kinship and marriage primarily allocate power to men, women depend heavily on them for access to things like food and healthcare. Studies reveal that despite their lack of information on women's health and disease, men in India and South Asia are the key decision-makers for women regarding health care services (Bloom S. et al 1997). Research also indicates that differences in socio-cultural norms of acceptable sexual behavior between men and women put women at greater risk of sexually transmitted infections (STIs) because of their partners' sexual behaviors. This is especially important during pregnancy when both the woman and fetus may be exposed to the risk of STIs.

If left untreated in women, STIs can cause infections leading to future infertility, pelvic inflammatory disease, abortions and stillbirths. In newborns, STIs can cause

\section{Collaborating with the Employees State Insurance Corporation, New Delhi}

The MiM study is underway in six dispensaries across $\mathrm{New}$ Delhi operated by the Employees' State Insurance Corporation (ESIC), an autonomous social security organization for industrial workers regulated by an Act of Parliament under the Ministry of Labour, Government of India. ESIC provides medical care and insurance to enrolled populations (workers earning less than Rs. 6,500 per month). In New Delhi, medical services are provided to approximately 2.2 million people through their network of five hospitals, standalone emergency facilities, daycare centers and 34 dispensaries. Young men living in low-income areas of $\mathrm{New}$ Delhi account for a major proportion of the caseload at these dispensaries.

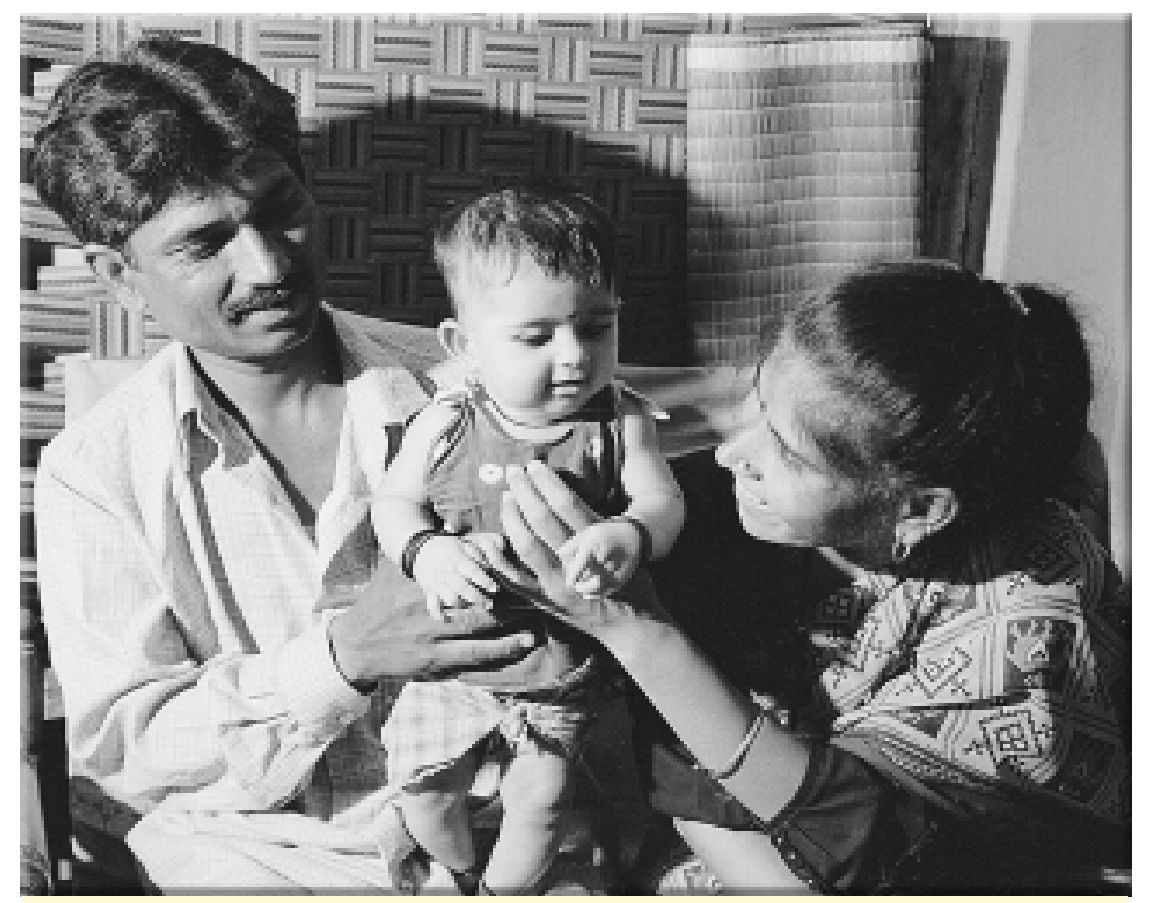

MiM study is the first of its kind in India involving men in antenatal and postpartum care. 
congenital infections such as gonococcal eye infections that can lead to blindness, or growth problems. STIs can also facilitate the transmission of and infection with HIV/AIDS in both men and women.

\section{Rationale for Intervention}

\section{The National Family Health SURVEY, INDIA (IIPS 2002) FOUND} that, in Delhi 84 percent of pregnant women received some form of antenatal care. This provides an ideal opportunity to introduce young couples to the benefits of family planning, and reinforcing these messages during the postpartum period can lead to an increase in family planning use (Simmons and Lapham 1987). The integration of STI-related services within maternity care settings (antenatal and postpartum care) has the advantage of making such services more acceptable and it helps ensure partner treatment, prevention of transmission to the fetus and risk reduction education.

ESIC provided full cooperation to the Population Council in improving existing services and adding on new components to the antenatal and postnatal services at the intervention dispensaries. Prior to the intervention it was found that services provided to pregnant women at ESIC dispensaries were similar to

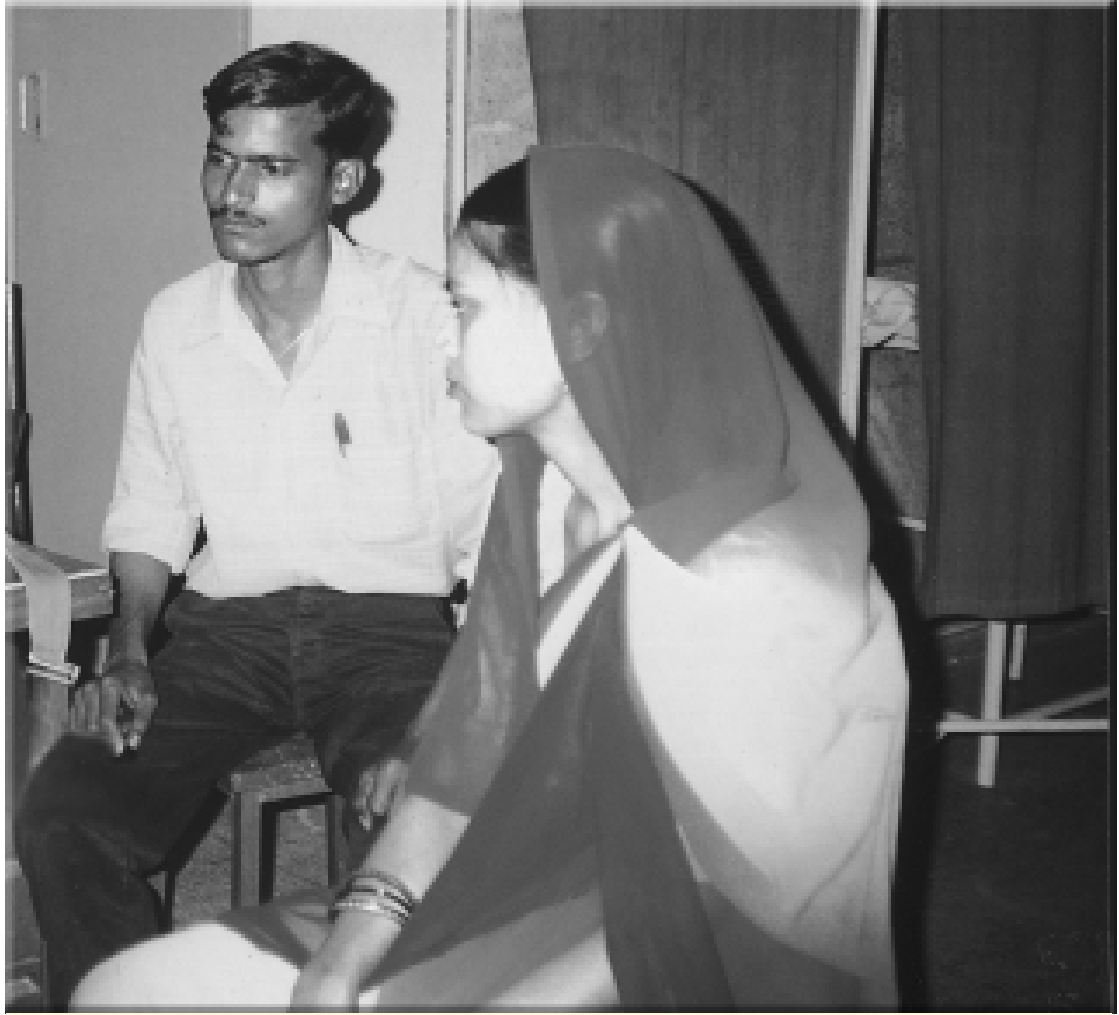

Husband accompanying his wife to the clinic - a shift from the earlier practice of visiting the clinic only when a referral was necessary.

the services at other primary healthcare settings in India where weekly antenatal and immunization clinics are held. On-site syphilis screening during pregnancy is not universally provided to all pregnant women. A routine six-week postpartum visit is not a part of services given, however child immunization is provided, including immunization for six-week-old infants. In general, providers tend to limit their interaction with clients to taking a brief history and providing some routine information on diet and rest during pregnancy because they feel pressured by the large numbers of clients in the generally crowded facilities. Men are usually allowed into the antenatal clinic rooms only when a referral to the hospital is considered necessary or when he acts as a translator for a woman who cannot understand the provider's language. Observation at the ESIC dispensary showed that 60 percent of women were accompanied by their husbands, who usually assisted their wives in queuing at the registration and laboratory counters, or looking after their young children. Women generally come during the late second trimester and most attend three clinic visits during their pregnancy before being referred to the ESIC hospital for registration and delivery. STI checks and treatment are not a routine part of the maternity services, though some providers do treat vaginal discharge symptomatically. Patients with an STI complaint are usually referred to a specialist at the referral centre. 


\section{The MiM Study} in India

\section{The MiM Study Utilizes A \\ NONEQUIVALENT CONTROL GROUP}

design. Three primary care

facilities (dispensaries) were

chosen for the experimental intervention while another three function as control sites. The study compares pregnancy and postpartum experiences of a cohort of 450 antenatal care couples drawn from the control dispensaries to a similar cohort from the intervention dispensaries for the same period of time. Figure 1 below illustrates the intervention timeline for individual couples. The clinic intervention began in December 2000 and will continue until December 2002 when the completion and analysis of the postpartum interviews will help assess the impact of the intervention and discussions on any adaptations or scaling up will be held with ESIC. The impact of the intervention will be assessed through standardized interviews conducted in both study groups.

The MiM interventions include a package of reproductive health services integrated within the existing antenatal services. The central elements of the study's intervention are:

1. Counseling and behavioral change and communication (BCC) materials about:

Postpartum family planning

- STI primary and secondary prevention practices, including condom use demonstration

- Symptoms of genital ulcer disease and male urethral discharge

- Benefits of immunizations and breastfeeding for infants

\section{Reproductive health care} service provision:

- Universal testing for syphilis (using RPR test kits) and appropriate

\section{Figure 1: Intervention Time-line for Individual Couples}

Couples are interviewed before receiving their first antenatal clinic visit and then at home at six months postpartum. The couple receives the intervention counseling sessions during early antenatal and six-weekspostpartum visits to the dispensary.

\section{Intervention Design}

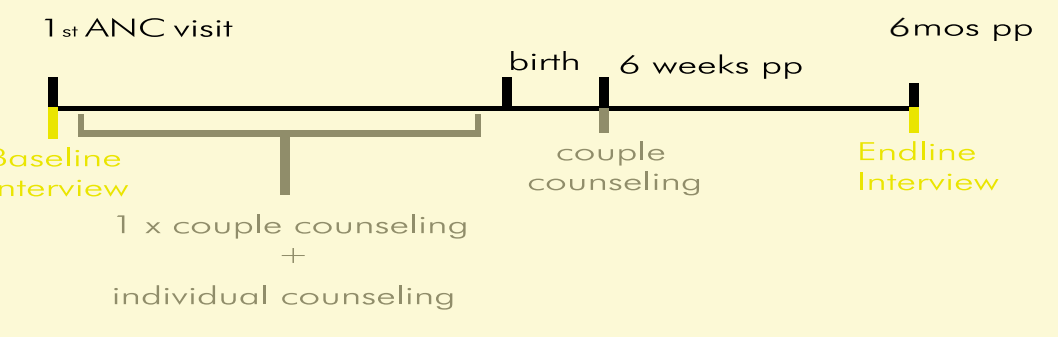

management and followup of all pregnant women testing positive (including partner notification, treatment and risk reduction BCC materials, as well as condom information, skill building and supply)

- Informing men about signs and symptoms of urethritis and genital ulcer disease and, if symptoms present, treatment using the national syndromic management guidelines

- Provision of a full range of appropriate postpartum contraceptive methods including Lactational Amenorrhoea Method (appropriateness refers to breastfeeding and STI risk status).

In addition to improving the quality and scope of antenatal care (ANC), the integrated ANC clinics provide a venue where husbands can receive reliable information about maternity care, STI prevention and treatment without the stigma attached to visiting STD clinics or the more woman-centered family welfare clinics.

INTRODUCING THE INTERVENTION at Antenatal Clinics

A core group of providers were identified in May 2000 and discussions on the intervention were held with them through monthly meetings until training of providers took place in November 2000. Providers were trained in family planning 


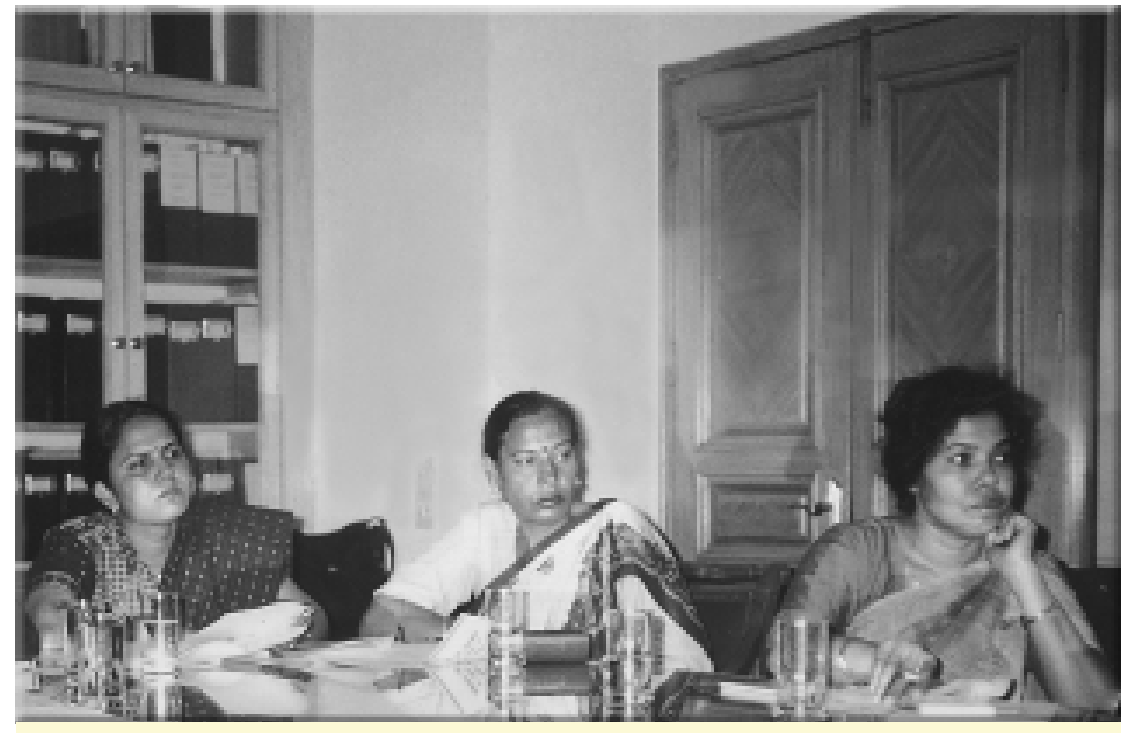

Providers being trained in family planning and STI counseling.

and STI counseling. A total of 12 auxiliary nurse mid-wives (ANMs) and 12 doctors were trained in all components of the intervention. The intervention was phased into service during a brief introductory period in December 2000 when all three intervention clinics began individual and couple counseling and universal antenatal syphilis screening for pregnant women. Problem solving discussions are held during the continuing monthly meetings.

Details of the initial assessment and training content are provided in an earlier Research Update No. 1 (March 2001). In January 2001, syphilis testing and family planning couple counseling, followed by individual or same-sex group STI counseling with condom demonstration, was initiated. Once the antenatal components of the MiM intervention were routinely provided, attention was given to increasing client attendance at the six-week postnatal clinics.

\section{BCC MATERIALS FOR THE INTERVENTION}

Two brochures were developed to reinforce messages that clients receive during antenatal visits:

\section{- The Maternity Care} brochure addresses both men and women and includes a page used as a client-held antenatal care record. It contains a record of the woman's antenatal clinic identification number, dates of visits and key results of lab tests. The card also works as a reminder for the next ANC appointment.

- The STI brochure is given to men, or to women when their husbands do not attend the clinic. The brochure contains condom-related illustrations and explains the correct use and protection it provides. It is particularly useful in situations where there is not enough privacy to provide an actual condom demonstration on a model.

These brochures were necessary because a single individual counseling session for pregnant women and their husbands covers a large amount of information within a short visit. Also, the brochures serve as a tool to support providers' counseling and gives information about topics for clients who are embarrassed to ask about STIs. The MiM study team also developed five posters aimed at low-literacy audiences for display on clinic walls. They were distributed to the intervention dispensaries in March 2001 and are on display in waiting areas and inside rooms used for the antenatal and postnatal check-ups. The five posters depict:

a man taking on household responsibility; using condoms to limit family size;

- using condoms to protect the unborn child from STIs;

- encouraging couples to attend antenatal clinics together; and

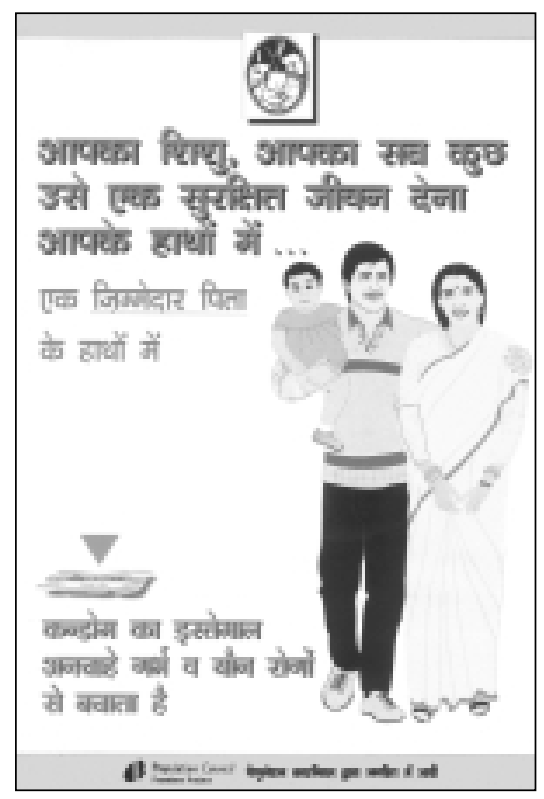




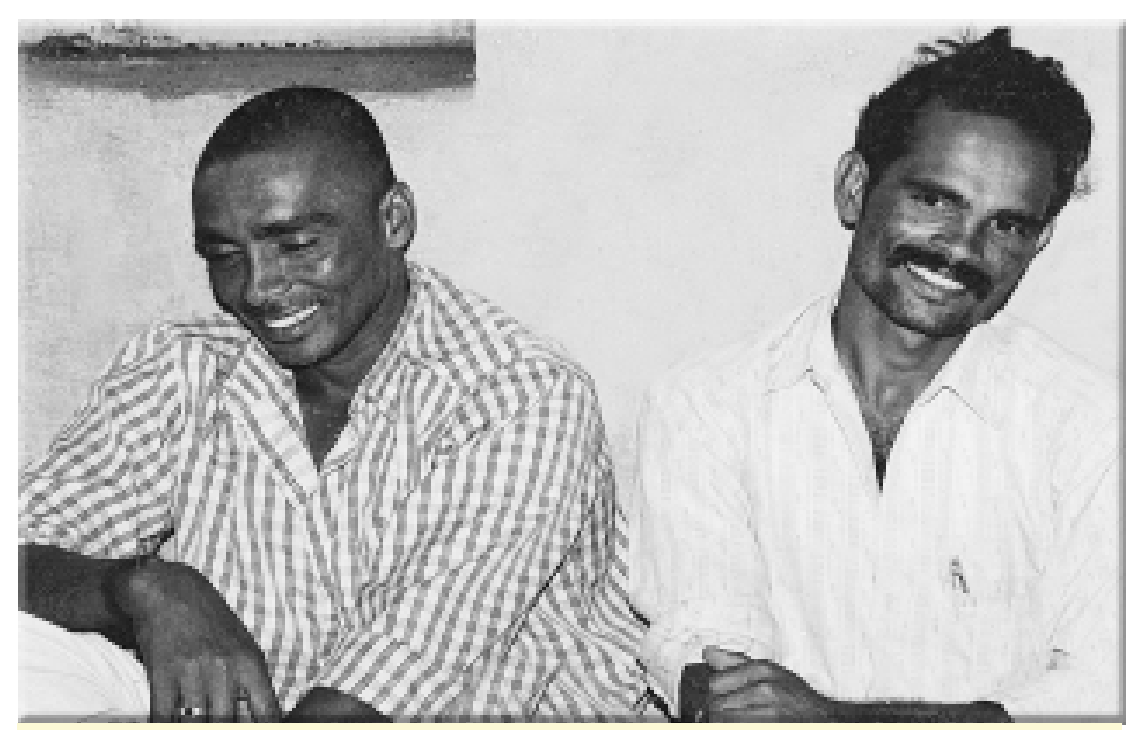

A group male counseling session in progress.

- explaining the three conditions of LAM for postpartum family planning.

\section{Couple Counseling Sessions}

Couple counseling sessions occur as part of the first visit at the antenatal clinic. After a woman indicates that she will allow her husband to participate in the intervention, he is called into the clinic and both husband and wife discuss pregnancy care and key counseling messages with the ANMs. After couple counseling, the husband is sent to a male doctor for individual male counseling and the woman receives a per abdomen antenatal check-up and an individual counseling session with the female doctor or ANM. A follow-up couple counseling session takes place at the sixweek postpartum visit.

\section{COUNSELING ON LAM}

The results from the baseline survey of clients revealed that none of the women correctly mentioned the three conditions under which Lactational Amenorrhoea Method (LAM) is an effective contraceptive method. Before training LAM was also not initially well understood by core providers. Information on LAM and its effectiveness postpartum as a family planning method for amenorrhoeic women who exclusively breastfeed during the first six months was communicated to couples through colorful and detailed posters made available at the dispensaries.
SEXUALLY TRANSMITTED INFECTIONS (STIS): RISKY BehaViors, PreVEntion and Management of SYMPTOMATIC CASES

Counseling related to STIs remains the most challenging component of the intervention to fully integrate into ESIC services. Despite the willingness on the part of individual doctors and ANMs to discuss sensitive issues with couples and demonstrate condom use on a penis model during their training session, in practice it was difficult to implement. One reason was the shortage of time for individual counseling sessions; another was the lack of privacy available at the sites coupled with widespread inhibitions among clients.

Originally doctors were trained to provide STI-related services while ANMs were trained to give couple counseling on family planning and maternity care. In practice, however, the women doctors spend much of their time with clients discussing obstetric care. Only

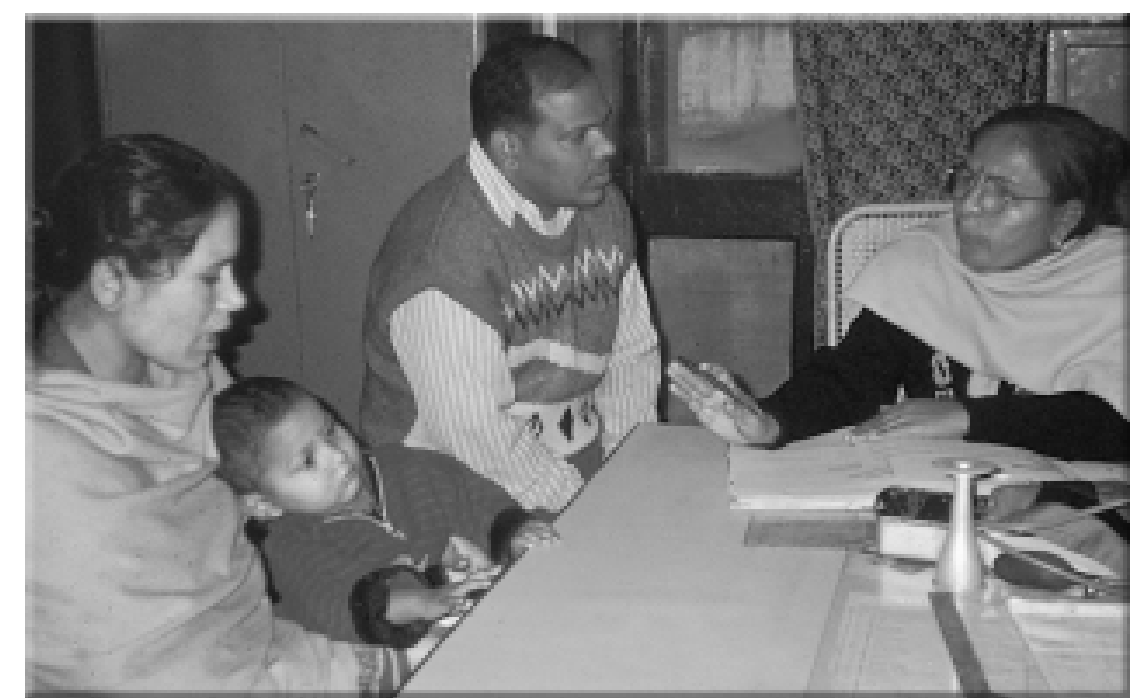

Couple counseling session underway. 
ANMs and male doctors discuss STIs and provide a condom usage demonstration to men and women.

As a solution, the project explored the option of hiring STI counselors. However, this was not possible without a formal policy change within ESIC to increase staff and existing constraints on space for an additional provider prohibited this avenue. In addition, there were concerns of sustainability. During initial discussions, providers felt that STI single-sex group counseling sessions would not work as a solution to reducing the amount of time for the counseling. Providers thought that clients preferred discussing potentially embarrassing issues individually. However, group sessions emerged as an effective tool for disseminating general information. In a similar manner, time and space constraints have been reconciled and providers' confidence to discuss potentially embarrassing information has increased.

Currently, most clinics are providing group counseling sessions on STIs. During these group sessions, individuals who desire private consultations are invited to seek the practitioners' advice.

\section{INTRODUCING UNIVERSAL ON-SITE SYPHILIS TESTING AND MANAGEMENT}

Syphilis testing of all pregnant women was not prevalent at the three intervention dispensaries before the intervention began. At only one dispensary, RPR (Rapid Plasma Reagin) testing had been introduced two years prior to the MiM study but not all pregnant women were screened.

As part of the MiM intervention, the laboratory technicians (LT) at all three clinics were trained in RPR testing. The LT was instructed to inform the doctor of all positive results. Currently 94 percent of all pregnant women attending the intervention clinics are screened for syphilis using the RPR test. Out of the 1,394 tests conducted, only two women have tested positive for syphilis using the RPR method in the past 14 months. The MiM intervention has shown that the presence of husbands at the antenatal clinics has ensured that spousal notification and treatment are more easily performed and condoms are provided to both partners. In a case where the infant was born, tests proved the baby was free from syphilis.

\section{INTRODUCING THE INTEGRATED MOTHER-CHILD Six WeEks Postpartum Visit}

Prior to the MiM study, parents were asked to bring their babies for immunizations at six weeks of age, and the mother did not receive any services at this time.

\section{Developing a Comprehensive Maternity Card}

Prior to the MiM intervention, ESIC dispensaries used their referral hospital's ANC form as their basic antenatal record, but this method of recordkeeping was often incomplete and inadequate.

Researchers and providers collaborated to develop a new "Maternity Card" to record information on couple and individual counseling sessions, RPR tests and highlighted risks, and to provide a record of delivery and contents of a postnatal care visit. The Card also functions as a tool kit for antenatal and postnatal counseling for service providers with counseling content checklists.

The Maternity Card was reviewed and pre-tested over a threemonth period, after which providers were trained in its use at the initial training sessions held in November 2000. Initially, providers had difficulty filling out the cards and so resisted its use. Gradually with assistance from the dispensary doctors and the Population Council staff, ANMs are valuing the Card's versatility for compiling reports and for ease of filling and filing.

The Cards are retained at the dispensary, and the clients receive the previously described maternity brochure, which also contains their personal pregnancy history and findings. Clients are requested to bring the brochure to every visit. A review of a sample of cards at the end of their first year in use shows that the Maternity Card has achieved its purpose - it is being used as a job aide and the records of services given and follow-ups are maintained prudently. 


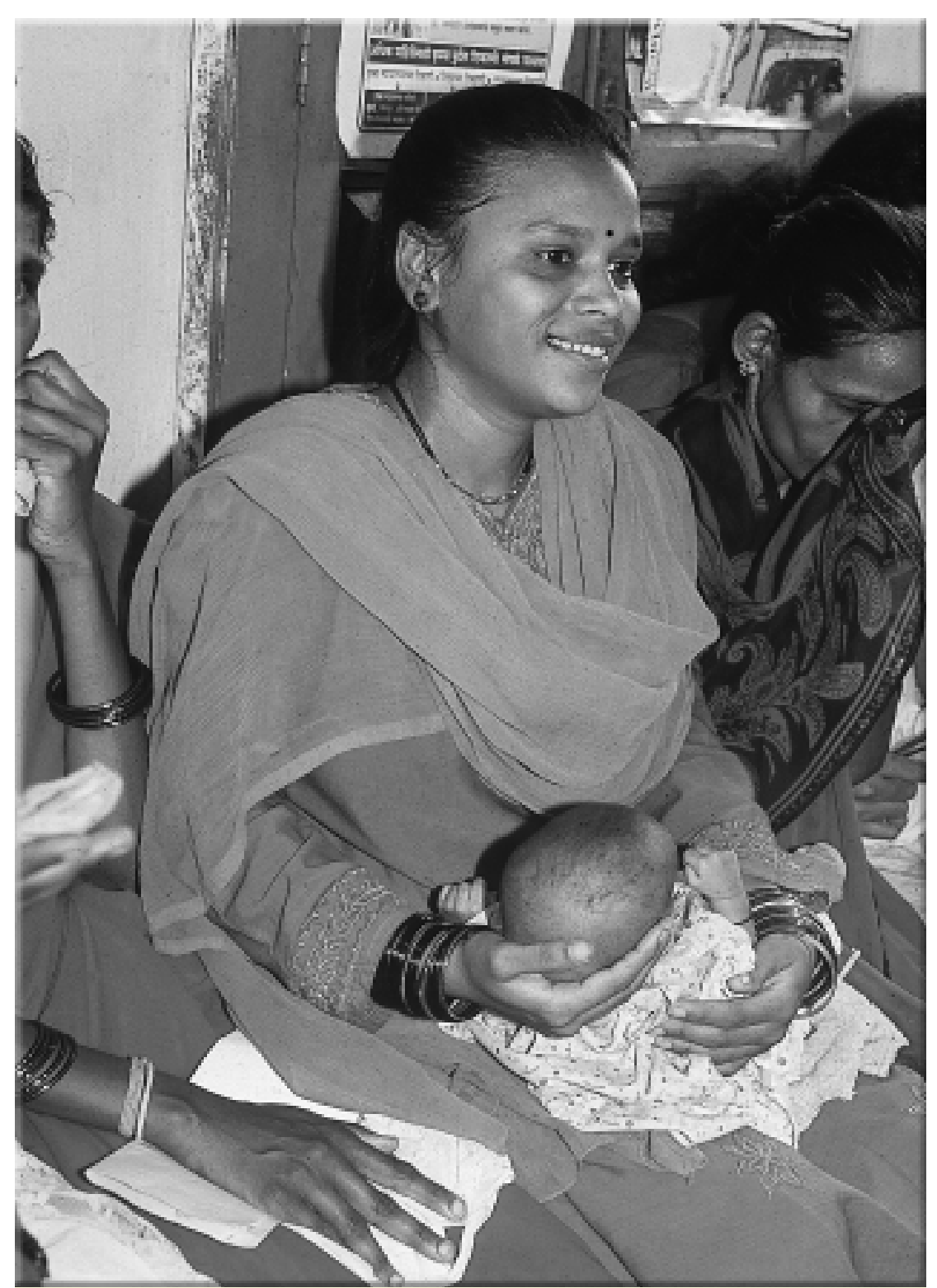

MiM integrated a postnatal checkup and couple counseling with child immunization at six weeks.

The MiM Study went one step further and integrated a postnatal check-up and couple counseling with child immunization at six weeks.

Couples receive counseling and tips on care of the infant, breastfeeding, family planning methods suitable in the postpartum period and prevention of STIs. Those who were treated for STIs in the antenatal period can be rechecked at this visit.

In practice, this postpartum visit has been difficult to implement since most women prefer to visit an immunization clinic closer to home and do not value a postpartum check-up of the mother. To improve this situation, providers emphasize the importance of a postpartum check-up for the mother and the need for a follow-up couple counseling session during antenatal sessions. An appointment for the postpartum visit is given to visit, which is noted in the client-held maternity brochure. The ESIC/Population Council MiM team is strategizing on couples in the antenatal period ways to increase couple attendance at the six-week postpartum visit.

\section{Mid-Course Corrections}

The MiM Study faced minor difficulties during the intervention phase, and members from ESIC and the Population Council collaboratively arrived at workable solutions. These corrections include:

- The lack of available space for male counseling is a problem. Doctors often provided STI-related counseling with little or no privacy. Some care providers were able to begin using a vacant room in the dispensary for more privacy. The MiM study team developed low costs screens for the survey that are now being used to partition rooms and provide more privacy.

- Pregnancy records and maternity information were not accurately and completely recorded, and clients often forgot to bring their earlier records to the dispensary. The MiM project team developed a comprehensive Maternity Card that records all relevant information for a complete ANC and PNC record for the client. (See the text box "Developing a Comprehensive Maternity Card" for more information). The card remains at the clinic and 
the client receives a maternity brochure with her ANC record number to bring to the clinic for each visit.

\section{- Staff rotation at ESIC} dispensaries occurred annually and required an investment of time to train new staff. The Population Council Research Officer provided comprehensive one-on-one training for new appointees involved with the intervention.

- Condoms were out of stock within three months after the intervention began. Dispensaries worked to borrow stock from other dispensaries until new stock arrived. New procedures are now in place to ensure that potential stock-outs are detected early and replenished.

Providers were reluctant to insert IUCDs at six weeks postpartum because they were unsure if the woman was pregnant or not. Providers were given a contraceptive technology update and shown how to use a checklist (developed by Family Health International, and translated into Hindi) for ruling out pregnancy and other contraindications to IUCD use.

Figure 2 above provides a summary, from service records, of the percent of clients who received new MiM services in the year 2001 .

Figure 2: MiM Intervention Service Statistics

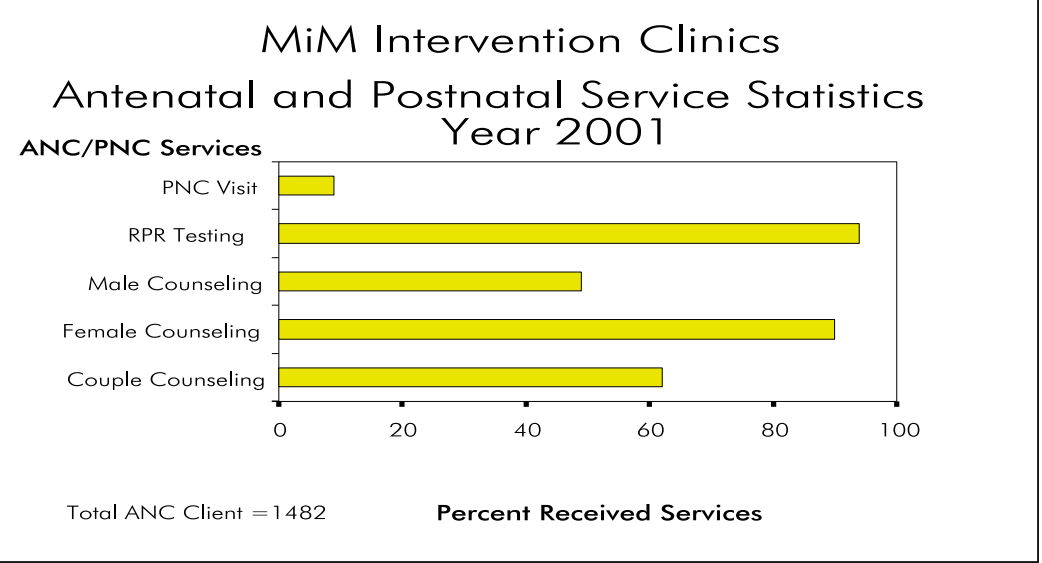

\section{Preliminary Results}

KEY ACCOMPLISHMENTS IN THE FIRST 14 MONTHS OF THE MIM INTERVENTION INCLUDE:

- The MiM project has succeeded in involving men in antenatal and postpartum clinics. 94 percent of pregnant women are now tested for syphilis and at least 60 percent of couples interact closely with providers and receive messages.

Providers now give more information to clients and their spouses on family planning, diet, rest, breastfeeding, emergency preparedness and the dual protection benefits of using condoms. Family planning services and syndromic management of urethral discharge and ulcers are emphasized. Condom demonstrations and STIrelated information are still not routinely provided at all
ANC visits. Efforts are being made at these dispensaries to improve STI counseling. ESIC decision-makers understand the importance of STI/HIV/AIDS prevention messages as part of the new services offered, and future links with HIV/AIDS prevention and treatment programs appear possible.

A comparison of antenatal clinic times spent with clients between control and intervention dispensaries shows that though there is not appreciable difference in client attendance, the time spent with each client has increased in the intervention clinics. In 2001, in all three interevention clinics 77 couples were counseled, on average, in a month. 78 percent of husbands who accompany their wives were counseled about STls, some individually and some in group male counseling sessions, when earlier no men entered the clinic room.

- The use of RPR test kits for screening pregnant women 


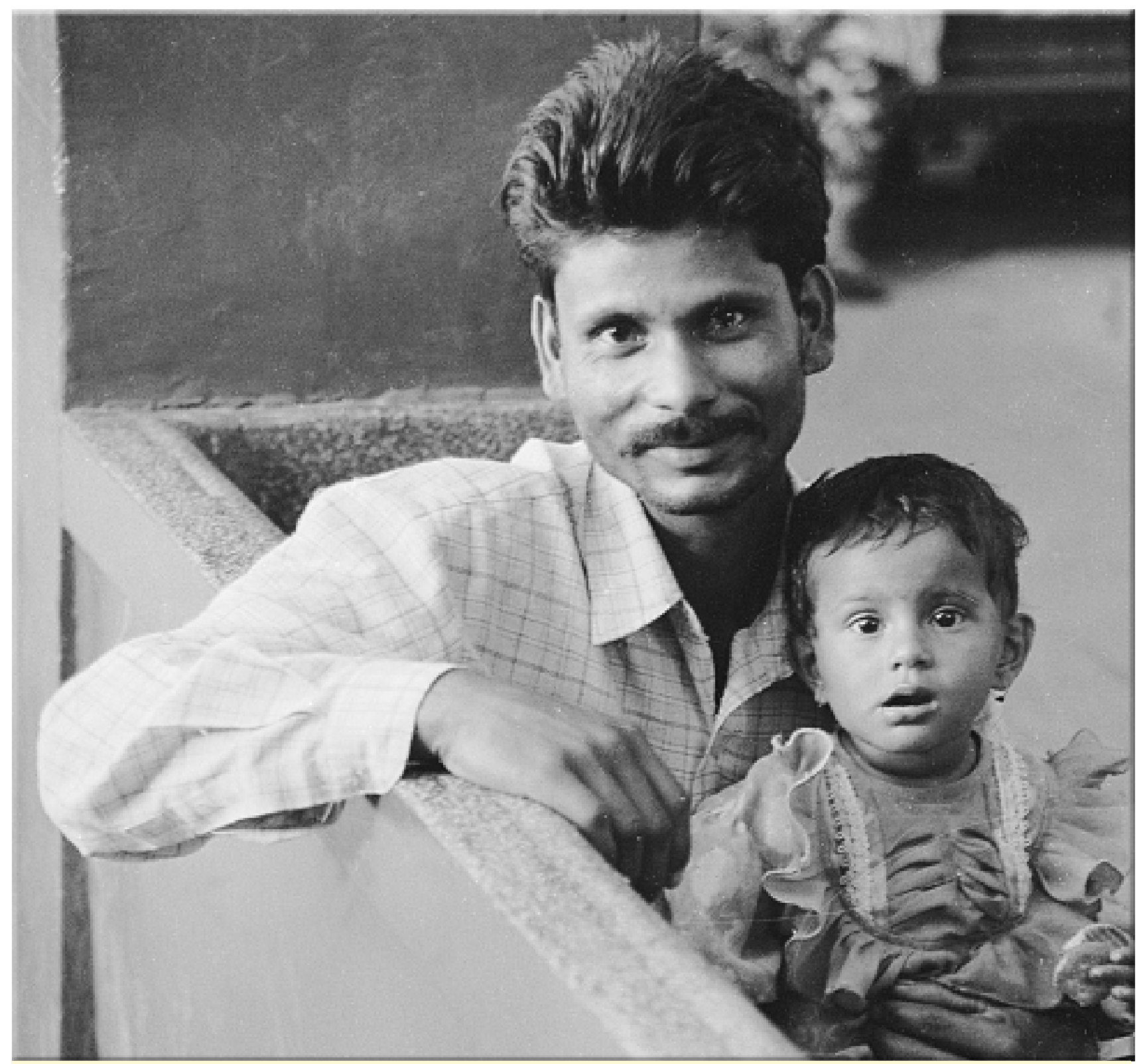

Men are becoming more aware of the critical role they play in $\mathrm{RH}$ and are seeking an active part as partners and as fathers.

for syphilis is now universal at all three intervention dispensaries and results are recorded and reported systematically. All these changes have been incorporated into existing clinic days with no extra staff recruited.

- Experience shows that the integration of the FP and STI components into existing maternity services and participation of men in maternity care are possible in $\mathrm{ESIC}$ dispensaries in
India. The six-month postpartum survey of clients who have participated in the intervention will begin in April 2002 and comparison of pre-post results from the baseline and postpartum surveys will allow an assessment of the impact of the intervention.

- The study is now in its second year of the intervention and providers are able to offer most of the services with confidence and with minimal increases in time spent per client.

During the remaining period of the study, senior officials from the Population Council and ESIC will meet to discuss a strategy for sustaining the intervention in the project sites. As findings from the postpartum survey become available and effectiveness of the intervention is proven, adaptation and/or replication of the MiM intervention at other ESIC dispensaries can be planned. 


\section{References}

Biddlecom, Ann E. John B. Casterline, and Aurora E. Perez. 1997 "Spouses views of contraception in the Philippines," International Family Planning Perspectives. 23(3): 108-115.

- Caleb Varkey, Leila. 2001. "Involving Men in Their Wives' Antenatal and Postpartum Care: Men in Maternity Update." FRONTIERS in Reproductive
Health, Population Council. New Delhi

- Bloom Shelah S., Amy O.Tsui, M. Plotkin, and S. Bassett . 2000. "What Husbands in Northern India Know About Reproductive Health: Correlates of Knowledge About Pregnancy and Maternal and Sexual Health". Journal of Biosocial Science. 2000 Apr;32(2):237-51.

- International Institute for Population Studies. 2002.

"National Family Health Survey, India 1989-99:

Delhi." International Institute for Population Sciences and ORC Macro. Mumbai IIPS

- Population Council and TNS MODE. 2002. "MiM Study Baseline Survey Report." FRONTIERS in Reproductive Health, Population Council.

- Simmons, George B., and Robert Lapham. 1987. "The Determinants of Family Planning Program Effectiveness." In Organizing for Effective Family Planning Programs. Robert J. Lapham and George B. Simmons (eds.), National Academy Press.

\section{(P) Population Council}

The Population Council is an international nonprofit, nongovernmental institution that seeks to improve the wellbeing and reproductive health of current and future generations around the world and to help achieve a humane, equitable, and sustainable balance between people and resources. The Council conducts biomedical, social science, and public health research and helps build research capacities in developing countries. Established in 1952, the Council is governed by an international board of trustees.

Copyright (c) 2002 The Population Council Inc.

This publication was made possible through support provided by the Office of Population, Health and Nutrition of the UNITED STATES AGENCY FOR INTERNATIONAL DEVELOPMENT (USAID), under the terms of Cooperative Agreement Number HRN-A-00-98-00012-00. The opinions expressed herein are those of the author and do not necessarily reflect the views of USAID.

\section{Frontiers in Reproductive Health Research} UPDATE, APRIL 2002

- Contributors:

Anjana Das, M.B.B.S., D.C.H.

Leila Caleb Varkey, Sc.D.

Anurag Mishra, M.P.S., M.Sc.

Emma Ottalenghi, M.D.

Dale Huntington, Sc.D.

Editing, Visualisation and Design:

Sohini Roychowdhury, PGDPR

Acknowledgement:

Chris Parker, M.A.*

*(Not Population Council staff)

Produced and Printed by:

macro graphics.comm pvt. Itd., New Delhi

For more information on the Frontiers Project, OR TO BE INCLUDED ON OUR MAILING LIST, PLEASE CONTACT US AT:

53 Lodi Estate, 3rd Floor

New Delhi 110003

India

Tel: $91-11-461-0913 / 4$

frontiers@pcindia.org 


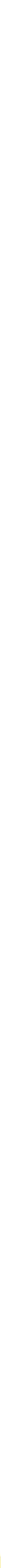

Frontiers in Reproductive Health

- INDIA

53 Lodi Estate

3rd Floor

New Delhi 110003

Tel: 91-11-461-0913/4

E-mail: frontiers@pcindia.org
- WASHINGTON 4301 Connecticut., N.W. Suite\#280

Washington, D.C. 20008

Tel: 1-202-2379400

E-mail: frontiers@pcdc.org 